\title{
Database Development of Land Use Characteristics along Major U.S. Highways
}

\author{
Demin Xiong \\ Center for Transportation Analysis \\ Energy Division
}

June 2000

Prepared for

Bureau of Transportation Statistics

U.S. Department of Transportation

\author{
Prepared by \\ OAK RIDGE NATIONAL LABORATORY \\ Oak Ridge, TN 37831 \\ managed by \\ UT-BATTELLE, LLC \\ for the \\ U.S. DEPARTMENT OF ENERGY \\ under contract DE-AC05-00OR22725
}




\section{TABLE OF CONTENTS}

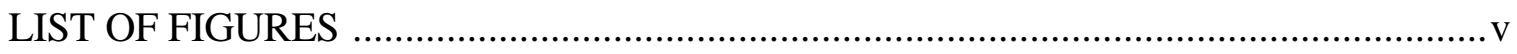

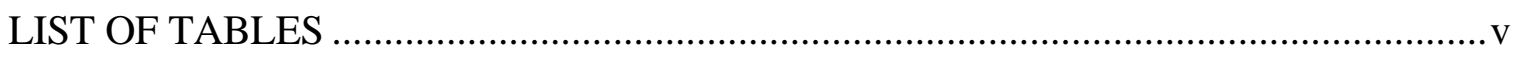

ACKNOWLEDGEMENTS ............................................................................. vii

EXECUTIVE SUMMARY ............................................................................. ix

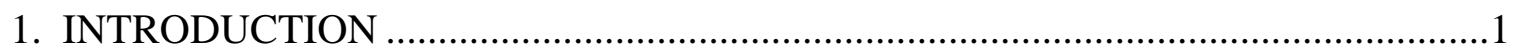

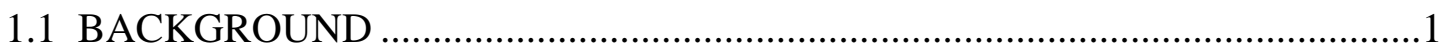

1.2 THE CURRENT EFFORT ....................................................................

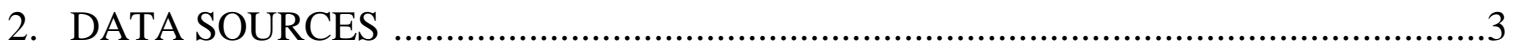

2.1 LAND USE AND LAND COVER (LULC) DATA …........................................

2.2 HIGHWAY PERFORMANCE MONITORING SYSTEM (HPMS) ...................4

2.3 NATIONAL HIGHWAY PLANNING NETWORK (NHPN) ...........................

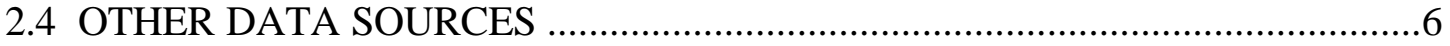

3. DATABASE DEVELOPMENT PROCEDURES …...............................................

3.1 HIGHWAY MILEAGE BY LAND USE TYPES .........................................

3.2 IMPACTED LAND AREAS BY LAND USE TYPES ….............................

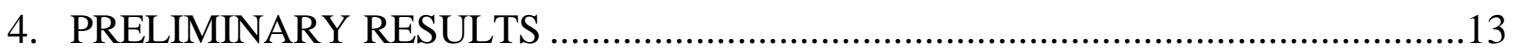

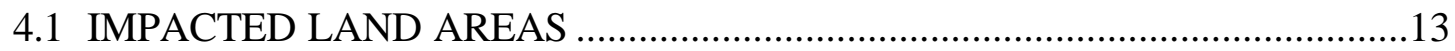

4.2 HIGHWAY LENGTH BY LAND USE TYPE.............................................. 14

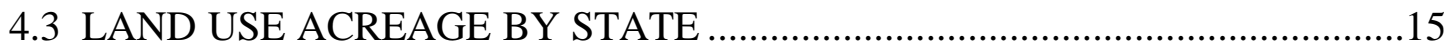

4.4 ACREAGE BY HIGHWAY TYPE BY LAND USE TYPE .............................15

5. CONCLUSIONS AND ADDITIONAL STEPS …................................................17

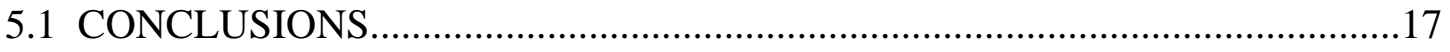

5.2 KNOWN PROBLEMS AND ADDITIONAL STEPS ….................................

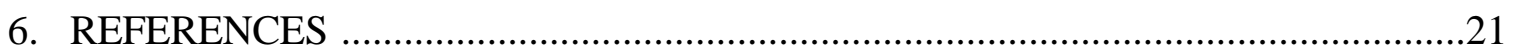

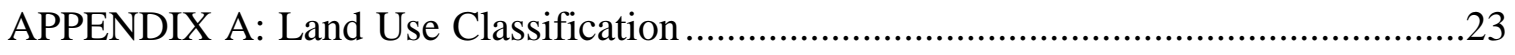

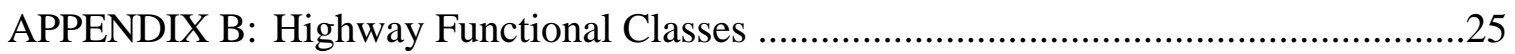

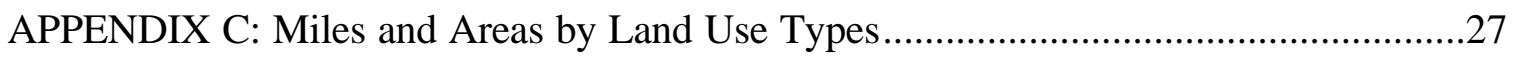

APPENDIX D: Miles and Areas by Functional Classes ..........................................29

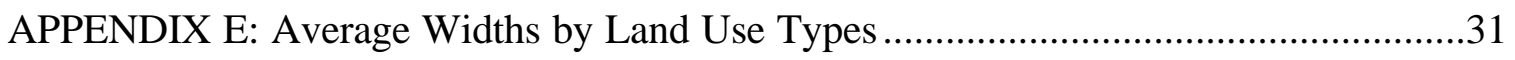


APPENDIX F: Average Widths by Functional Classes

APPENDIX G: Areas by Highway Type by Land Use Type 


\section{LIST OF FIGURES}

Figure 1. An Overlay of an LULC Map and the NHPN ............................................4

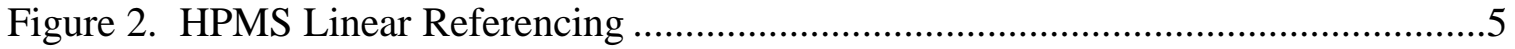

Figure 3. Problems with Simple Overlay of the LULC Map and the NHPN ...................8

Figure 4. Resolving Land Use Types Along Highways .........................................

Figure 5. The HPMS Sample Interpolation and Extrapolation...................................10

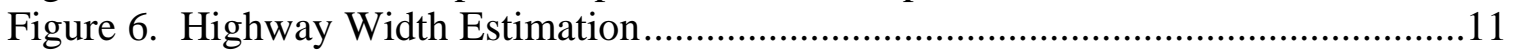

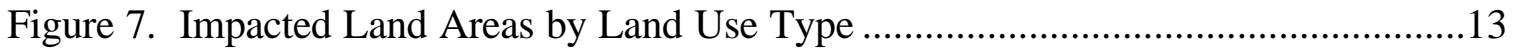

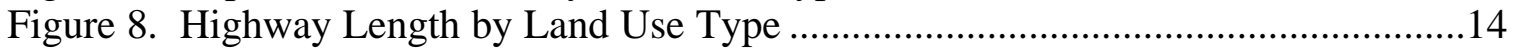

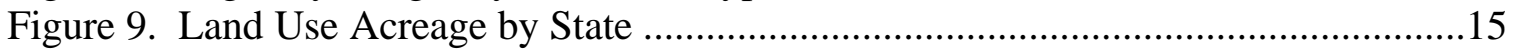

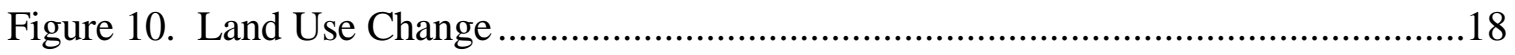

\section{LIST OF TABLES}

Table 1. Land Use Types Along Highways ............................................................

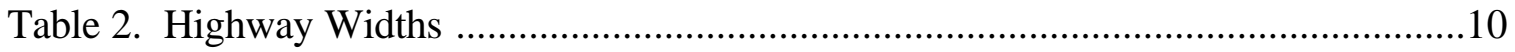




\section{ACKNOWLEDGEMENTS}

The author wishes to thank David Greene for his advice in conducting this research and preparing this report. Thanks are also due to S. M. Chin, Ho-Ling Hwang, Bruce Peterson, and Frank Southworth for their suggestions and discussions in project meetings. 


\section{EXECUTIVE SUMMARY}

Information about land use by and adjacent to transportation systems is essential to understanding the environmental impacts of transportation systems. Nevertheless, such data are presently sparse and incomplete, especially at the national scale. To address the need for land use data, the Bureau of Transportation Statistics (BTS) and Oak Ridge National Laboratory (ORNL) undertook the development of land use data for major U.S. highways. This report describes data sources, methodology and preliminary results of this research.

To develop the land use database, data from three major sources were utilized: (1) National Highway Planning Network (NHPN), (2) Highway Performance Monitoring System (HPMS), and (3) the 1:250,000- and 1:100,000-Scale Land Use and Land Cover (LULC) Data from the U.S. Geological Survey (USGS). The NHPN is used to establish the geographic location of highway networks and provide attribute data (e.g., highway name, functional type, state and county flags, etc.) to support data analysis. Overlays of LULC data and the NHPN generate mileage of different land use types along highways. Interpolation and extrapolation using HPMS sample data results in estimates of widths of pavement, median and right of way for each highway link on the NHPN. Based upon mileage of land use types and highway widths, land use statistics, such as mileage of different types of land use along highways, and land areas occupied by highway infrastructure are generated.

It is estimated that the total land area or right of way given to highways that are represented in the NHPN for the continental United States is 7,634,872 acres, among which pavement accounted for 2,173,052 acres, medians for 612,966 acres, and the rest of the right of way for $4,848,854$ acres. Highway land use data are also established by the miles and areas, by land use types and by highway functional classes, and can be aggregated or broken down into different geographic regions or administrative areas (e.g., counties or states).

It must be pointed out that the numbers provided in this report should be considered preliminary and current estimation of transportation-related land use has some known problems. Primarily, the use of the simple overlay of the NHPN and USGS maps results in significant errors in over-counting of urban land. Because many highway links represented in the NHPN fall inside the highway polygons of the LULC maps, the simple overlay procedure cannot resolve land use types along these highway links directly. Consequently, land use types along these highways are not correctly reported. The lack of currency of LULC maps is another major concern. Many LULC maps were created with data collected about 20 years ago. Significant changes on land use have taken place since then, which adds additional errors to the current statistics.

The report identifies some of the strategies to overcome these problems and recommends additional steps to be taken for improvement of both methods and data. The possibility of using remote sensing data and more detailed transportation networks to extend the scope of the current work to include compete roadways and other mode of transportation systems is discussed. 


\section{INTRODUCTION}

\subsection{BACKGROUND}

The major objective of the effort reported here is to develop methods to measure transportation land use at the national level (i.e., how much land and what types of lands are used by transportation systems) and to track changes over time. Data for transportation-related land use are important for environmental analysis, climate change studies, transportation-land use interaction research, policy decisions related to urban sprawl, and more.

Transportation systems have direct effects on the environment through modification of vegetation, impacts on wildlife habitats, changes in local climate and alternation of drainage patterns (U.S. DOT/BTS, 1996; U.S. DOT/BTS, 1998; U.S. EPA, 1999; Maggi, 1994; Verhoef, 1994). However, without accurate and complete land use data, it is extremely difficult to study and evaluate these effects. Transportation systems also induce land use changes. Such indirect effects, while not the subject of this study, may be more significant than the direct land-use impacts of transportation infrastructure. Establishing an inventory of transportation infrastructure and adjacent land use and maintaining the inventory over time is an important first step towards understanding the full range of interactions between transportation and land use.

While current and historic land use data are essential for investigating the relationships between transportation and land use, so far, no technological or institutional mechanisms have been established to systematically collect such data at the national level. The lack of long-term planning in land use data acquisition can be a major setback for future research in transportation land use studies. Land use data also play a key role in the understanding of problems related to urban sprawl and in policy decisions in dealing with these problems.

\subsection{THE CURRENT EFFORT}

The work described in this report is a first step toward establishing a national land use database for U.S. transportation systems. The current work focuses on developing land use data for major U.S. highways. The database we have created contains land use type, highway length, and widths of pavement, median and right of way for each major highway class. With this database statistics such as highway miles for different land use types, land areas given to pavement, median and right of way, and land use areas on different land use types, and so on, are now available at state and national levels.

In the course of creating the database, we also established a procedure that can be utilized to integrate data from diverse sources. The procedure with some extension, such as the inclusion of more detailed networks (e.g., the U.S. Census TIGER files) and the use of 
more extensive samples (e.g., samples through high-resolution images), will allow more complete land use measures for the entire transportation system at the national level. The rest of the report is organized as follows: Section 2 describes data sources used for the land use data development. Section 3 outlines technical procedures for deriving the land use database. Section 4 presents more extensive coverage on the results, and Section 5 analyzes problems associated with these preliminary results and prescribes additional steps to improve current estimates. 


\section{DATA SOURCES}

Three types of data are used in this study: 1:250,000 and 1:100,000 scale Land Use and Land Cover Maps by the U.S. Geological Survey (USGS), Highway Performance Monitoring System (HPMS) by the Federal Highway Administration (FHWA), and National Highway Planning Network by FHWA. This section provides a description of each of these three data sets. Toward the end of the section, several other data sets that are not directly utilized in the current work, but may have potential usefulness in the future, are also evaluated.

\subsection{LAND USE AND LAND COVER (LULC) DATA}

The LULC data used in this project were originally collected by USGS and converted to ARC/INFO export data format by the U.S. Environment Protection Agency (EPA). These data were created for environmental assessment with respect to water quality analysis, growth management, and other types of environmental impact assessment. The data are organized with subdivisions in the form of a quadrangle. There are 370 quadrangles in total, covering the entire continental United States, with one quadrangle missing in central Texas.

Data for different quadrangles were collected at different dates within the period from mid 1970s to early 1980s. Because of these differences, land use types and boundaries near the edges of quadrangles may not match. In some cases, an edge-matching algorithm has been applied to remove overlaps or gaps between adjacent maps. The Anderson classification system (Anderson et al., 1976) was adopted to code the land use types for the LULC series, but only the top two levels of classification (e.g., level 1 and level 2) are actually utilized. At the top level (level 1), there are nine land use categories: 1-Urban or built-up land, 2-Agricultural land, 3-Rangeland, 4-Forest land, 5-Water, 6-Wetland, 7-Barren Land, 8-Tundra, and 9-Perennial snow or ice. Each category at the top level is further divided into subcategories (e.g., Urban or built-up land has seven subcategories, including: 11-Residential, 12-Commercial or services, 13-Industrial, 14-Transportation, communication, utilities, 16-Mixed urban or built-up land, and 17-Other urban or built-up land).

Both the scale and the classification systems of the USGS LULC series fit the current purpose very well, especially since the data are going to be overlaid with the NHPN, which is at a scale of about 1:100,000. This provides reasonable compatibility in terms of resolution and details. Figure 1 gives a sample LULC map overlaid with NHPN roads, providing an idea about the resolution of the LULU map and the relationship between road networks and land use patterns. 


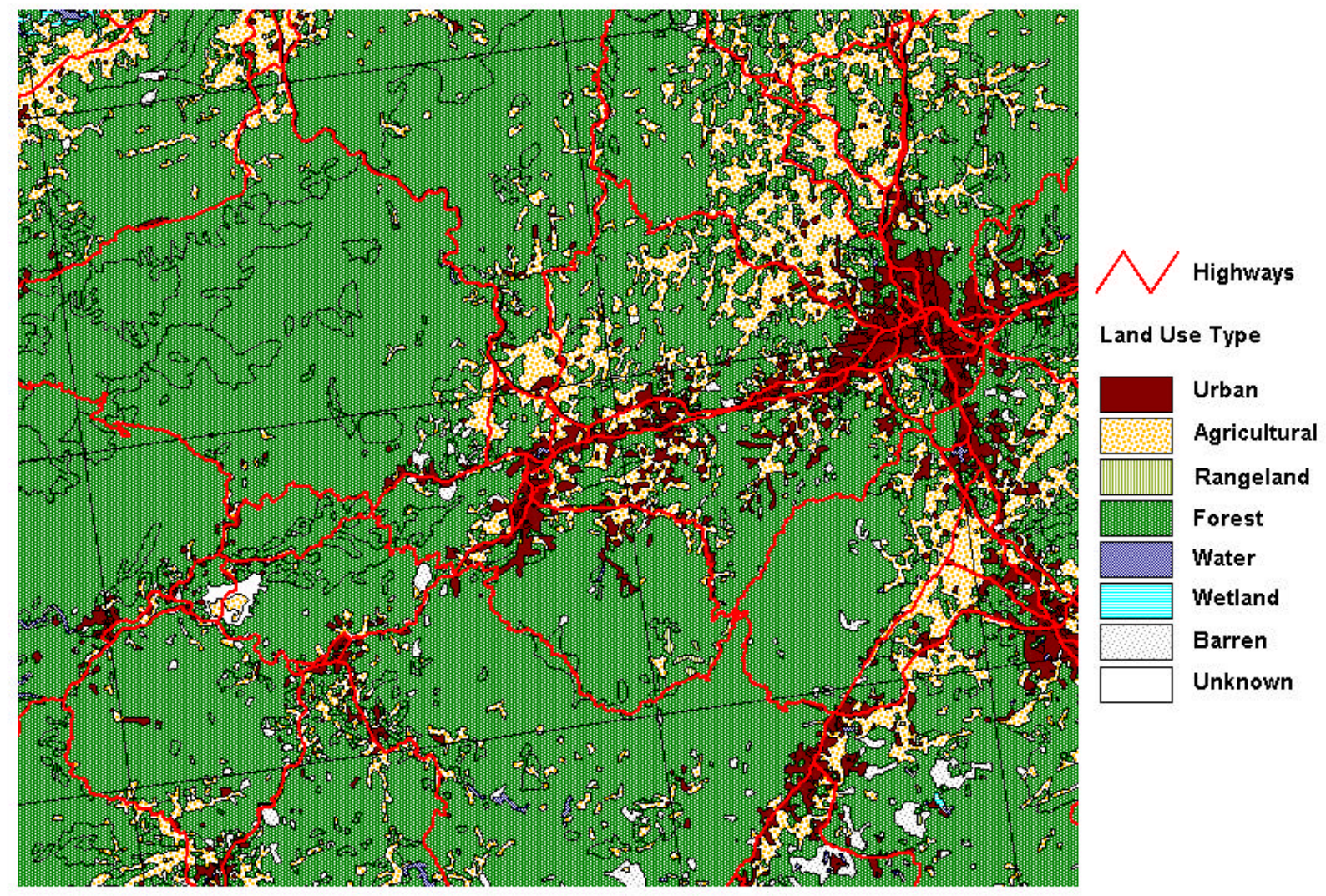

Figure 1. An Overlay of an LULC Map and the NHPN

The classification system has sufficient details for representations of land use characteristics. Only the level 1 classification is used in this study. The major concern with the USGS LULC data, however, is its currency. In some areas, especially those close to large cities, land use patterns have changed significantly since these maps were created. Nevertheless, the USGS LULC series still represents the most complete land use map series for the United States at the largest scale, and currently there is no practical alternative.

\subsection{HIGHWAY PERFORMANCE MONITORING SYSTEM (HPMS)}

The HPMS data are assembled from the data that are collected by state highway agencies, local governments and metropolitan planning organizations. These data are updated annually and divided into four major categories: the statewide summaries, universe data for the entire public road system, standard sample data and "donut" area sample data, and the HPMS linear referencing system (LRS). For the current project, the 1997 standard sample data and the LRS data are used. The standard sample data include detailed highway engineering data that cannot be found in the universe data. Even though these sample data are limited to sample sections, it is believed that data collected on the sample 
sections are representative of similar conditions on associated highway links, so that the sampled data can be expanded to cover the rest of the network. The most useful data items in the standard sample data are the number of traffic lanes and widths of traffic lanes, shoulders, median and right of way.

As HPMS data are provided in a tabular form, they cannot be displayed as a map directly. LRS data are provided to address this problem. LRS data define route systems in such a way that each route will have a unique LRS ID, and a starting point. Any road segment in the network now can be uniquely identified with an LRS ID and a from-mile point and an end-mile point, as illustrated in Figure 2. As the same sign route may split and discontinue, referencing data using LRS is still not as simple as using latitude and longitude, which creates some difficulties in the use of the data.

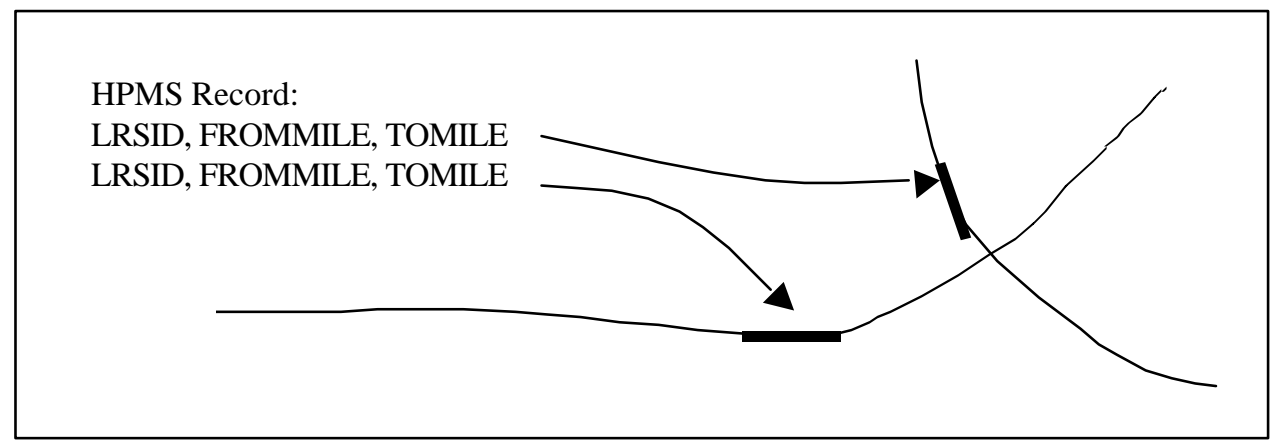

Figure 2. HPMS Linear Referencing

\subsection{NATIONAL HIGHWAY PLANNING NETWORK (NHPN)}

The NHPN is part of the National Transportation Atlas Database that is distributed by the U.S. Bureau of Transportation Statistics (BTS). It currently contains the entire National Highway System (NHS) and other major highways. The NHPN was initially derived from USGS 1:100000 Digital Line Graph and several other sources, which have a position accuracy of about $100 \mathrm{~m}$. Given this accuracy, it is sufficient for us to use the NHPN as a referencing framework to integrate and geographically register the derived land use data.

Data items, such as sign route number, number of lanes, functional categories, rural/urban road classification and county and stage FIPS code associated with each road section presented in NHPN, are also extremely valuable. For instance, continuity along sign routes, as well as roads with similar functional classes, can be exploited to expand sample HPMS data to other road sections. Functional categories, rural/urban classification, and county and state FIPS codes are also useful for generating land use statistics, such as land areas by functional class, by county and by state, etc. 


\subsection{OTHER DATA SOURCES}

Several other data sources were also evaluated in the course of this effort. These data sources include the National Wetlands Inventory (NWI) by U.S. Fish and Wildlife Service (USFWS), data from the Multi-Resolution Land Characteristics (MRLC) and the National Gap Analysis Program (GAP), U.S. Census Bureau's TIGER Files, and highresolution digital images from space- or air-borne sensors. Even though these data are not currently used, they may have potential uses in the future.

A. National Wetlands Inventory (NWI): NWI is currently an ongoing effort in USFWS. The inventory contains $44,000+$ map files, mostly at the scale of 1:24K, but some at the scales of $1: 25 \mathrm{~K}, 1: 20 \mathrm{~K}, 1: 62.5 \mathrm{~K}$, etc. When completed, it can provide more detailed information on the characteristics, extent, and status of the Nation's wetlands and deepwater habitats. At the present stage, utilizing these data is still difficult because of data volumes and incompleteness. Also, not all the maps are currently made available in the digital form.

B. MRLC and GAP: The MRLC and GAP represent a major effort to develop new LULC maps at the 1:100000 scale for the continental United States. The scale appears to be appropriate for the development of transportation land use data at the national level. The main problem, however, is that the LULC maps generated through this program are still largely unavailable.

C. TIGER files: TIGER files are ancestors of many exiting road network databases. There are some problems with currency, but TIGER files should be satisfactory for purposes of land use studies and land use statistics, especially at the national level. In the future, we may be able to replace the NHPN with TIGER files so that land use data can be collected at a more detailed level.

D. Aerial photos and satellite images: Digital aerial photos and satellite images, panchromatic or multispectral, can be utilized for both road measurement and land use classification. For instance, these data can be utilized to update outdated land use maps and to sample road networks more extensively. With these data and data from TIGER Files, the USGS LULC maps and other ancillary data sources, we could attain a much more complete land use measurement of transportation systems for the entire nation. A parallel effort supported by the ORNL Laboratory Director's R\&D fund has been underway to develop methods to extract land use information from highresolution images. The results of this effort will be utilized in the next stage of the land use data development. 


\section{DATABASE DEVELOPMENT PROCEDURES}

The goal of this project is to estimate two types of data for highway land use: (1) mileage by land use types, and (2) impacted land areas by land use types. For type 1 data, we would like to measure precisely what types of land use and how long a highway link will traverse these types of land. For type 2 data, we would like to provide an account of how much land is given to transportation infrastructure including pavement, median and right of way. In the following sections we describe the procedures used to derive these data.

\subsection{HIGHWAY MILEAGE BY LAND USE TYPES}

The desired data can be represented by a table containing lengths of different land use types along highways as shown in Table 1. In the table, each record corresponds to an NHPN link. The NHPN link ID is utilized to identify each record so that it can be matched easily with NHPN attribute data. The L1 through L9 represent the fields that contain lengths for the nine categories of land use types at the level 1 classification of the Anderson system. L10 is set aside for representing unknown categories if any are present.

Table 1. Land Use Types Along Highways

\begin{tabular}{|l|l|l|l|l|l|l|l|l|l|l|}
\hline LINKID & L1 & L2 & L3 & L4 & L5 & L6 & L7 & L8 & L9 & L10 \\
\hline ID-1 & L1_1 & L2_1 & L3_1 & L4_1 & L5_1 & L6_1 & L7_1 & L8_1 & L9_1 & L10_1 \\
\hline ID-2 & L1_2 & L2_2 & L3_2 & L4_2 & L5_2 & L6_2 & L7_2 & L8_2 & L9_2 & L10_2 \\
\hline ID-3 & L1_3 & L2_3 & L3_3 & L4_3 & L5_3 & L6_3 & L7_3 & L8_3 & L9_3 & L10_3 \\
\hline$\ldots \ldots$ & $\ldots \ldots$. & $\ldots \ldots$. & $\ldots \ldots$. & $\ldots \ldots$. & $\ldots \ldots$. & $\ldots \ldots$. & $\ldots \ldots$. & $\ldots \ldots$. & $\ldots \ldots$. & $\ldots \ldots$. \\
\hline ID-N & L1_N & L2_N & L3_N & L4_N & L5_N & L6_N & L7_N & L8_N & L9_N & L10_N \\
\hline
\end{tabular}

To generate this table, the following procedures are utilized. First, the NHPN is overlaid with the USGS LULC maps, which usually results in multiple segments for each NHPN link (each segment has a unique land use type). Then the length of each segment is calculated, and the lengths for those segments that belong to the same NHPN link are aggregated based upon land use types. Finally the lengths of different land use types along a highway link are normalized so that these lengths will add to exactly the link length given by the NHPN.

The NHPN and USGS LULC overlay is an overlay of lines and polygons, which is implemented using the ARC/INFO GIS software package. In general, map overlay is a routine operation in GIS, and can generate reliable and accurate results. One problem we encountered in using this simple overlay procedure, however, is that some highways are represented as polygons in the LULC maps, and when the NHPN links are intersected with the LULC highway polygons, the actual land use types along highways cannot be resolved. That is, when NHPN links fall in the LULC highway polygons, those links will 
have a land use type of highway, instead of the land use type along the highway (Figure 3).

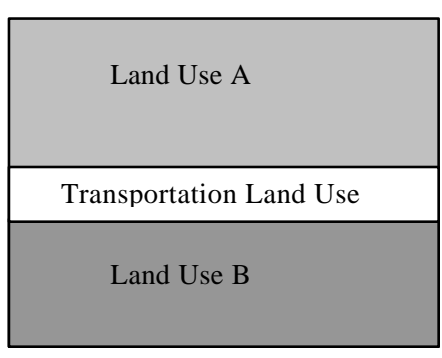

a. LULC map

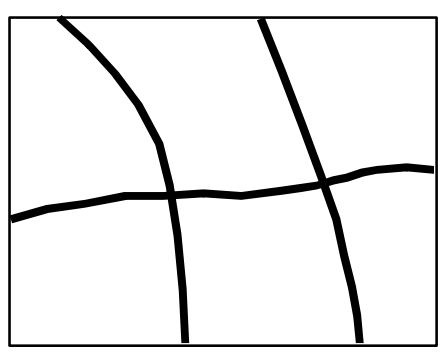

b. NHPN network

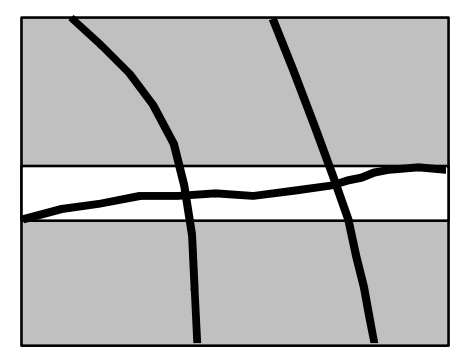

c. overlay

Figure 3. Problems With Simple Overlay of the LULC Map and the NHPN

To deal with the problem, we have tried to correlate LULC polygons with NHPN links, then resolve the land use types along a highway; but given the complexity of the polygon shapes on the LULC maps, this method cannot generate reliable results. Currently we are investigating another simpler method. The main idea of this alternative method is that after the overlay, a follow-up procedure will be utilized to first find those NHPN segments that are located inside LULC highway polygons, then search for segments on LULC polygon boundaries that are parallel to the NHPN segments. By identifying the outer land use types of these parallel segments and measuring their lengths, the NHPN segments will be assigned with mileage of different land use types along the highway segment (Figure 4.) Alternatively, highway polygons can be bisected with centerlines. Then land use types that are adjacent to highway polygons will be assigned to the bisected polygons.

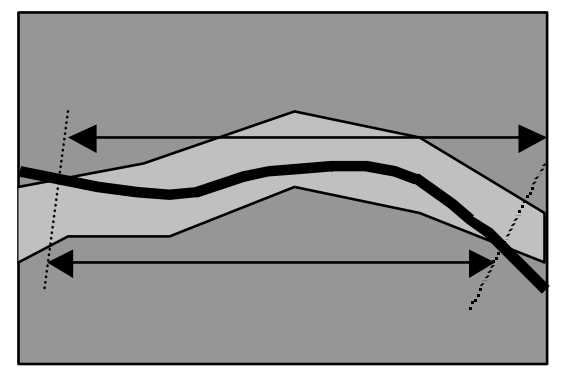

Figure 4. Resolving Land Use Types Along Highways

After polygon overlay, highway links are usually split into multiple segments, each representing a specific land use type. To obtain a measure of the mileage for different land use types, a length calculation procedure is followed, and the segment shape points 
are directly used in this calculation. Then segments that belong to the same NHPN link are aggregated to form a single entry in the database table. This aggregation is done using a simple computation as follows:

$$
\begin{gathered}
L 1=\sum l_{i} \text { for all } i \text { 's that havethe land use code } 1 \text { for Andersonlevel -1 classification } \\
\ldots . . . . .
\end{gathered}
$$

Here $L 1 \sim L 10$ represent ten different land use types as described earlier, and $l$ is the length of a segment with a specific land use type. After this aggregation, a table similar to Table 1 is established. One additional step is followed to ensure that computed lengths for all the land use categories for a highway link will add up to the exact length that is given by the NHPN file. To do so, the computed lengths for different land use categories are normalized with a factor:

$$
F_{j}=L_{j} /\left(L 1_{j}+L 2_{j}+L 3_{j}+L 4_{j}+L 5_{j}+L 6_{j}+L 7_{j}+L 8_{j}+L 9_{j}+L 10_{j}\right),
$$

where $j$ is the link ID, and $L j$ is the length given by the NHPN; $L 1_{j}, L 2_{j}, L 3_{j}, L 4_{j}, L 5_{j}, L 6_{j}$, $L 7_{j}, L 8_{j}, L 9_{j}$, and $L 10_{j}$ represent the computed lengths for each categories of land use along the highway link.

\subsection{IMPACTED LAND AREAS BY LAND USE TYPES}

The task of measuring land areas given to transportation infrastructure requires estimates of highway widths for pavement, median and right of way, as shown in Table 2. $W 1, W 2$, and $W 3$ represent the fields of pavement width, median width and width of right of way separately. Once these widths are obtained, land areas can be computed with the following:

$$
A_{i j k}=L_{i j k} \bullet W_{i j k}
$$

where $j, k$, and $i$ represent the land use type, width type (e.g., pavement, median, and right of ways), and the highway link ID respectively. $L$ is the length of a specific type of land use along a highway link. $W$ is the width with respect to pavement, median, and right of way, and $A$ is the land area to be computed. 
Table 2. Highway Widths

\begin{tabular}{|c|c|c|c|}
\hline LINK_ID & W1 & W2 & W3 \\
\hline LINK_ID_1 & W1_1 & W2_1 & W3_1 \\
\hline LINK_ID_2 & W1_2 & W2_2 & W3_2 \\
\hline LINK_ID_3 & W1_3 & W2_3 & W3_3 \\
\hline$\ldots \ldots$ & $\ldots \ldots$ & $\ldots \ldots$ & $\ldots \ldots$ \\
\hline LINK_ID_N & W1_N & W2_N & W3_N \\
\hline
\end{tabular}

To create the width table, a spatial interpolation and extrapolation procedure was utilized to expand the HPMS samples to the entire NHPN. Figure 5 illustrates how the procedure works. The thick, short segments parallel to the arrowhead lines shown in Figure 5 represent HPMS samples. For a link that is not an HPMS sample, the best way to estimate the width for that link is to find the closest sampled links along a path that have the same route number or route sign, or functional class, then take the average of the widths of those closest sample links or simply the width of the single closest link as an estimate.

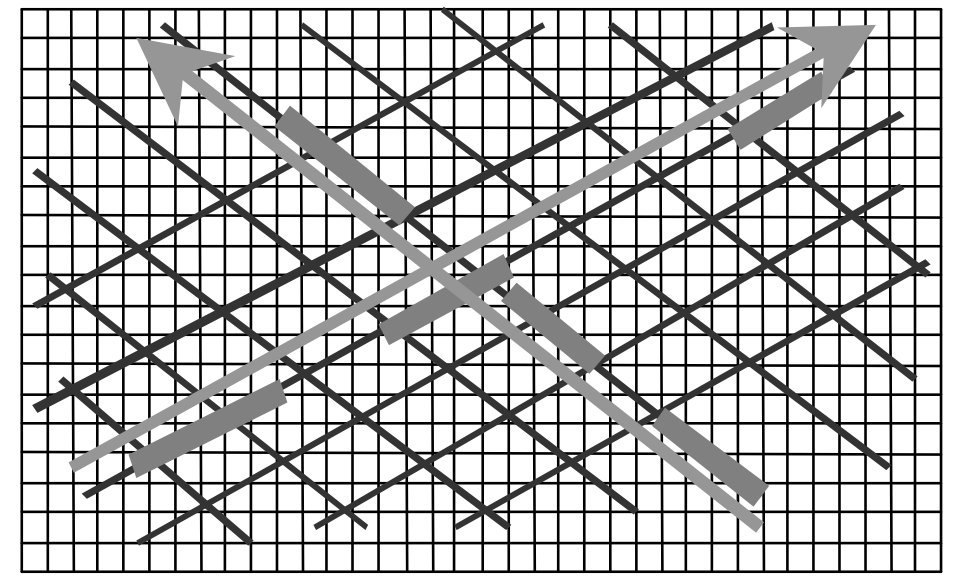

Figure 5. The HPMS Sample Interpolation and Extrapolation

To implement this procedure effectively, we created a grid system that allows each link to be spatially referenced. To do so, when a link, $e_{j}$, is selected for width calculation, links that are close to $e_{j}$ will be identified quickly by locating links in the grid where $e_{j}$ is located and in other nearby grids.

To find the nearest sample links, a list is used to first store all the links that are close to $e_{j}$, and then order the list using the distances and directions of the selected sample links relative to the link $e_{j}$. Finally, the nearest link in each of the two opposite directions will be identified. In general, two possibilities exist: One is that there are two sampled links identified as the nearest links, each in an opposite direction. In this case, the average width of these two nearest links is used as an estimate of the width for $e_{j}$ (we consider this as an interpolation). The other possibility is that there is only one nearest link found. 
In this case, the link $e_{j}$ will take the width of that nearest link (we consider this as an extrapolation). Other interpolation and extrapolation alternatives are also possible (e.g., more than one or two nearby links are selected and ordered, then first-order and/or second-order derivatives are used to derive an estimate, which may be useful for median and right-of-way estimations when they change gradually along highways).

During the process of interpolation and extrapolation, we also found that some of the NHPN links cannot be identified with the route sign (e.g., their route sign fields are empty), or no HPMS samples can be found associated with a given NHPN link. In these circumstances, the above-described interpolation and extrapolation procedure cannot work properly. To complement the interpolation and extrapolation procedure, we also devised a backup procedure using state and county averages. This backup procedure makes use of pre-computed tables that contain average widths for each functional class at both the county and the state levels. When a link cannot be assigned a width with the interpolation and extrapolation procedure, this backup procedure takes over, and assigns an average width to this link based upon the functional class of the link.

The overall process of width calculation is shown in Figure 6. It proceeds with two stages: initialization and computation. During the initialization stage, state averages and county averages are prepared and grid indexes of HPMS samples are established. During the computation stage, interpolation and extrapolation are first applied to resolving link widths. If link widths cannot be obtained by interpolation and extrapolation county averages will be checked. If link widths are still not assigned after checking county averages, state averages will be assigned to the link. The initial widths computed include widths for traffic lane, left shoulder, right shoulder, median and right of way. These widths are then aggregated to generate the widths for pavement, median and right of way.

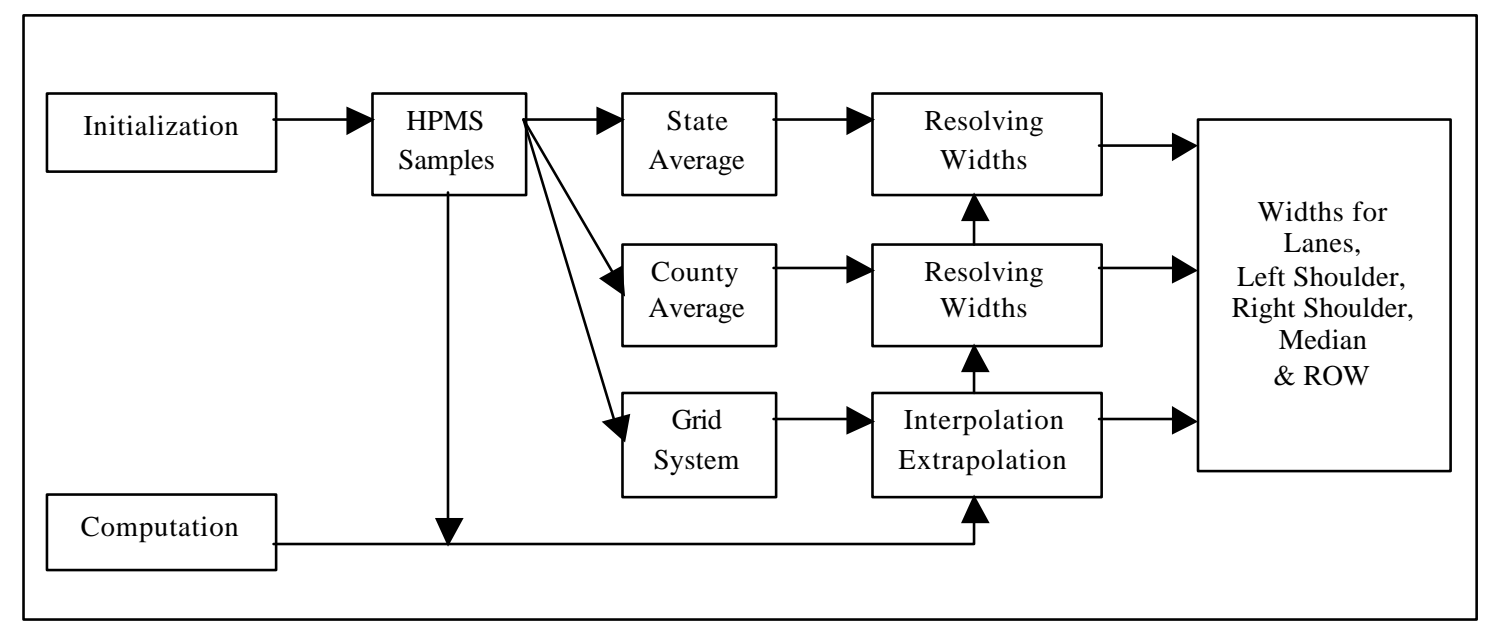

Figure 6. Highway Width Estimation

Once the widths for pavement, median and right of way are estimated, a simple calculation (as described earlier in this section) can be used to compute the land areas for 
highways. As each link may have up to ten categories of land use types, and each land use category can have separate accounts for pavement, median and right of way, a total of 30 data items for each link are used to record land use areas by land use types and by pavement, median and right of way. 


\section{PRELIMINARY RESULTS}

With the procedures described in Section 3, a land use database for major continental U.S. highways represented in the NHPN was created. Using this database, it is estimated that the total land area or right of way given to highways that are represented in the NHPN is 7,634,872 acres, among which pavement accounted for 2,173,052 acres, medians for 612,966 acres, and the rest of the right of way for 4,848,854 acres. To have a more detailed account on highway land use, categorized statistics are also generated. These statistics include: (1) land areas occupied by highways by land use types, (2) highway mileage by land use types, (3) highway land use by states, and (4) areas by highway types and by land use types.

\subsection{IMPACTED LAND AREAS}

Figure 7 provides the total land areas occupied by different land use types (see Appendix $\mathrm{C}$ for additional details). Land use types are coded according to the level 1 Anderson classification (see Appendix A for type description). Impacted land areas include areas for pavement, medians and the rest of the right of way.

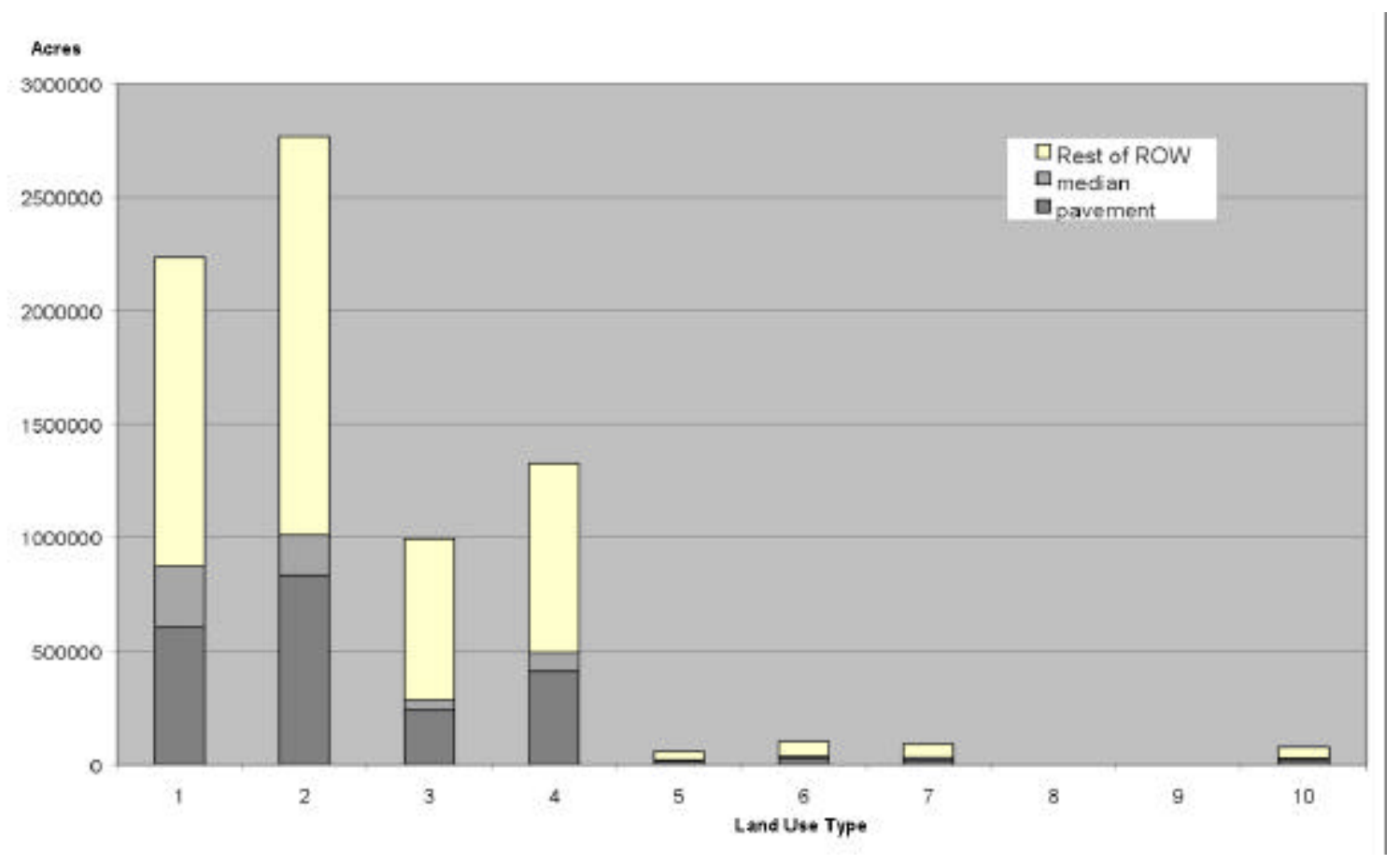

Figure 7. Impacted Land Areas by Land Use Type 
As shown in Figure 7, agricultural land is the most frequently taken for highway use, accounting for about 2.75 million acres in total, among which 1.75 million acres are given to right of ways, 0.2 million acres given to medians, and 0.8 million acres given to pavement. Next is urban or built-up land, accounting for 2.2 million acres in total, comprised of 1.3 million acres given to right of ways, 0.3 million acres to medians, and 0.6 million acres to pavement. Rangeland and forestland are also significantly impacted, with totals of 1.0 million acres and 1.3 million acres separately. In comparison, wetlands are one of the smallest acreage categories. But given the fact that the total acreage of wetlands is also a small fraction of the total land area, the ratio of impacted wetlands acreage to total wetlands acreage might be a more appropriate measure.

\subsection{HIGHWAY LENGTH BY LAND USE TYPE}

Highway mileage by land use type shows a pattern similar to the chart of impacted land areas, as illustrated by Figure 8. There are subtle differences though: the relative lengths of urban versus agricultural land appears larger than the ratio between land areas for urban and agriculture. We believe that this is because transportation as a land use category is contained by the urban and built up class. This problem, which was discussed above in section 3.1, must be resolved in future analyses.

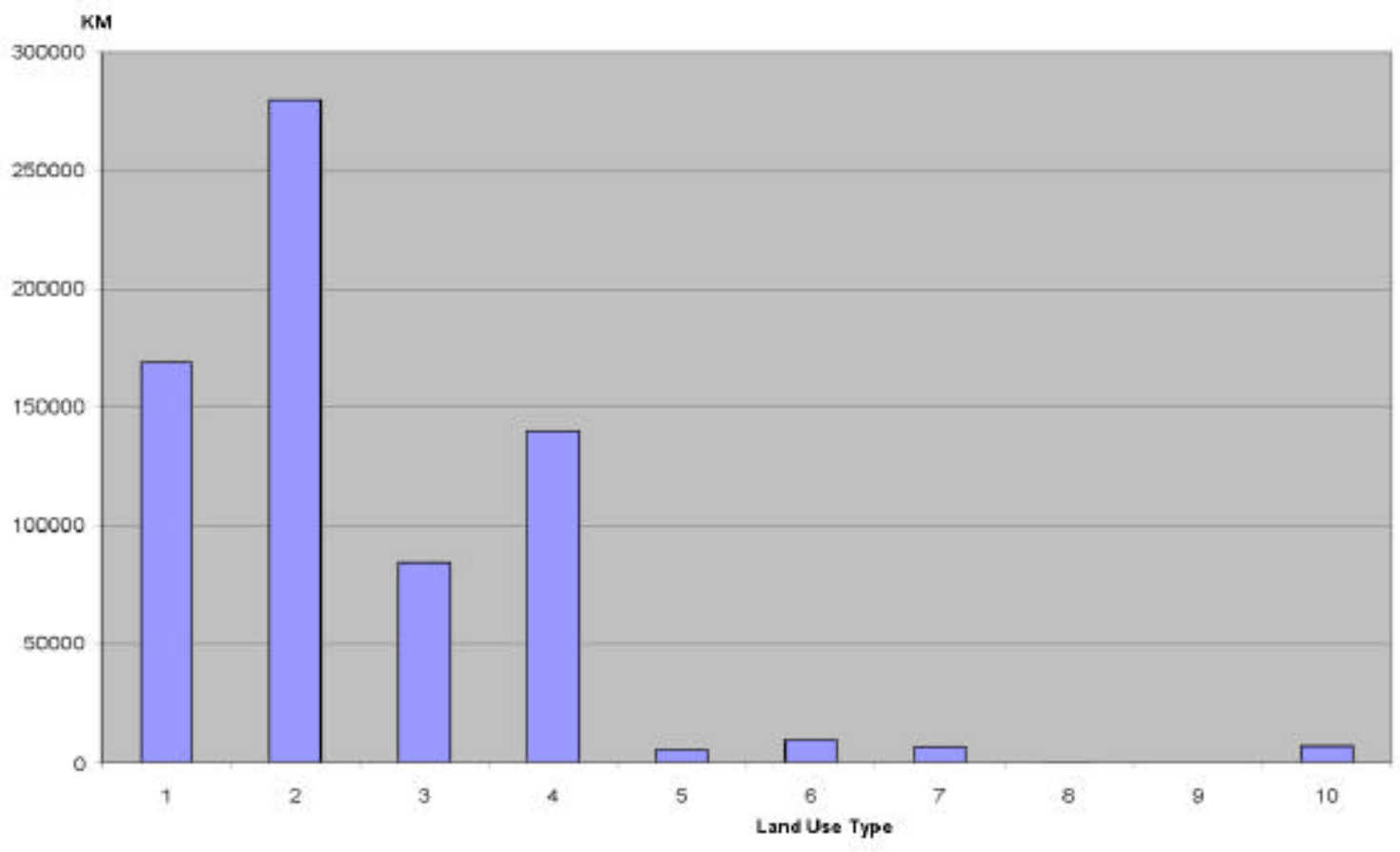

Figure 8. Highway Length by Land Use Type 


\subsection{LAND USE ACREAGE BY STATE}

Figure 9 is a map representing land use acreage by state. From the map, it is apparent that Texas has the highest acreage for highway land use, with a total of about 0.71 million acres. A relatively large proportion of the land area in Texas is given to highway rightof-ways. California ranks second, with a total of 0.37 million acres. The ratio between these two states may seem out of order, but this is because roads included in NHPN don't represent the actual road density in a state. To have meaningful comparisons for total road land use between different states, complete road networks or a complete network of a specific road category (e.g., interstate highways) must be measured.

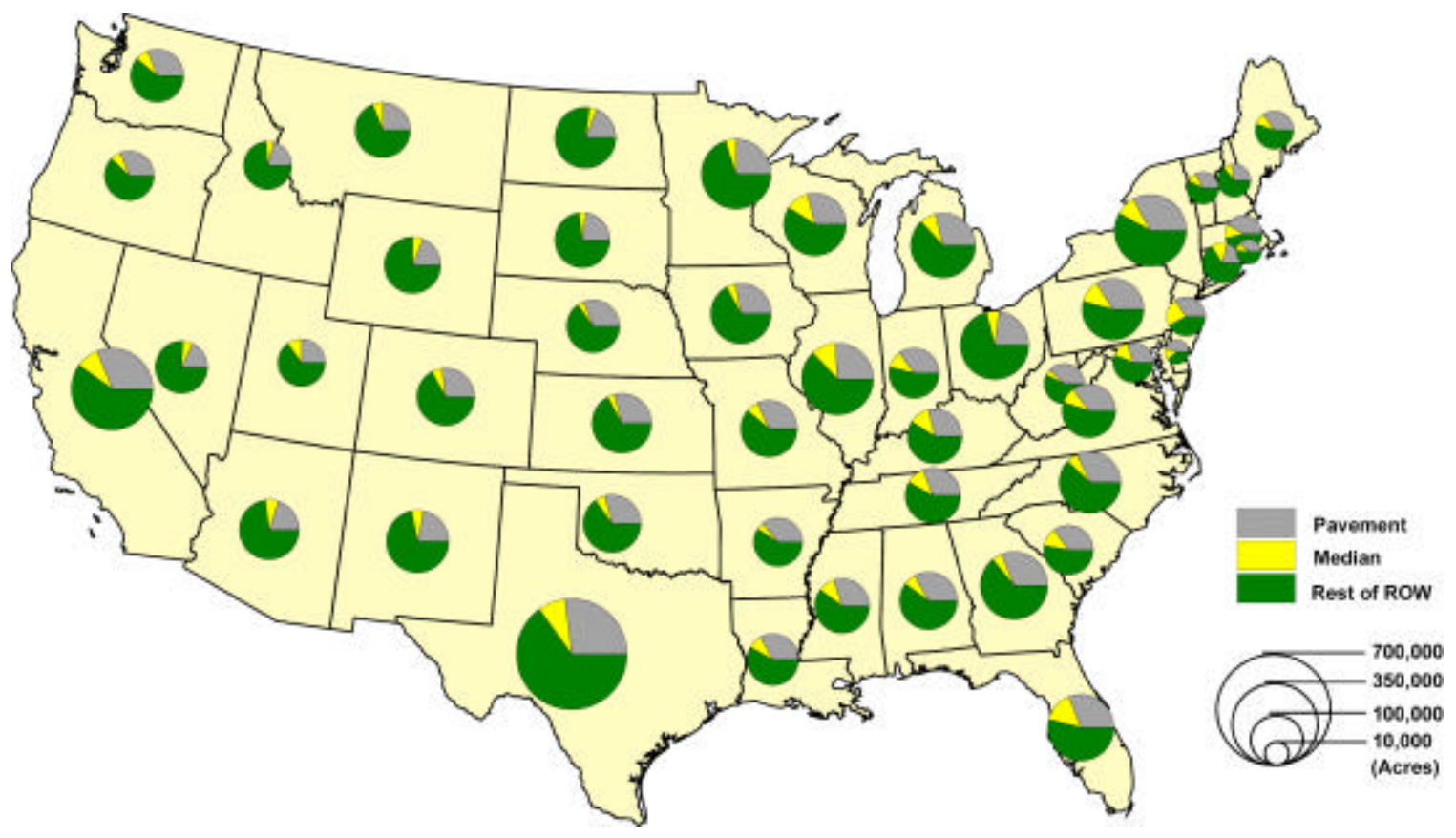

Figure 9. Land Use Acreage by State

\subsection{ACREAGE BY HIGHWAY TYPE BY LAND USE TYPE}

Appendix G shows land use area by highway type by land use type. The land use types are coded as described earlier. Highway types are based upon the Functional Classification used in NHPN and HPMS (see Appendix B for description). In addition to the divisions of highway types and land use types, highway land use is further divided into three categories: pavement, medians and the rest of the right of way. Such a detailed categorization may provide information for applications such as runoff calculation by different functional classes.

Although more statistics can be generated and reported here, as pointed out in the next section, there are some known problems with the current results, namely that the land use 
data are out-of-date, and the aforementioned methodological problem with the category of transportation land use. The numbers provided in this report should be considered preliminary and the report's chief contribution lies in the development and demonstration of new methods for estimating transportation's land use impacts. 


\section{CONCLUSIONS AND ADDITIONAL STEPS}

\subsection{CONCLUSIONS}

The current study has produced a land use database associated with major U.S. highways. This database contains information on highway land use by highway functional class for ten land use types, for pavement, median and right of way. Using this database, statistics such as highway miles for different land use types, land areas given to pavement, median and right of way, land areas given to different land use types can be generated quickly.

A procedure has been developed and implemented that makes use of sampled data and existing transportation networks. When using more detailed networks and more extensive samples this procedure could be used to estimate land use data for the entire transportation system in a cost-effective manner. It is also worth mentioning that in developing this land use database, we have successfully integrated specialized dataprocessing procedures with existing GIS functions. With this approach, we were able to effectively manage, process and validate a large of amount of data.

\subsection{KNOWN PROBLEMS AND ADDITIONAL STEPS}

Several problems with the current data and methods need to be noted. These problems have been recognized, but due to time constraints have not been adequately addressed. One of the problems mentioned earlier is the use of the simple overlay of the NHPN and USGS maps. Because many highway links represented in the NHPN fall inside the highway polygons of the LULC maps, the simple overlay procedure cannot resolve land use types along these highway links directly. At present, these links are assigned to urban or built-up land. Consequently, the results reported in Section 4 contain errors with a bias toward the over-counting of urban land use. To get an idea about the problem, we checked the mileage of highway-on-highway vs. the total mileage for some selected areas and found that for those selected areas, the average mileage of highway-on-highway links accounts for about five percent, with a high at about ten percent and low at 0.4 percent off the total land area given to transportation. Fixing the problem using the procedure proposed in Section 3 would be an important task for any future work.

The lack of currency of LULC maps is also a major concern. Figure 10 shows part of the Atlanta Metropolitan Area, where land use has experienced significant changes in the last two decades. The dark background shows urban or built up land use about 20 years ago. To get a picture of how land use patterns have changed between then and now, the NHPN network is differentiated with a rural/urban flag (thin symbol for rural and thick symbol for urban) and overlaid on the land use map. Through this overlay it is clear that on the fringe of the urban areas, many roads now have an urban flag on the NHPN, but were not identified as urban land on the LULC map. To address this problem, land use maps especially in areas close to big cities must be updated. The use of remotely sensed data and the use of databases developed from land use data collection activities such as 
National Wetlands Inventory (NWI) and MRLC and GAP programs are important avenues to explore here.

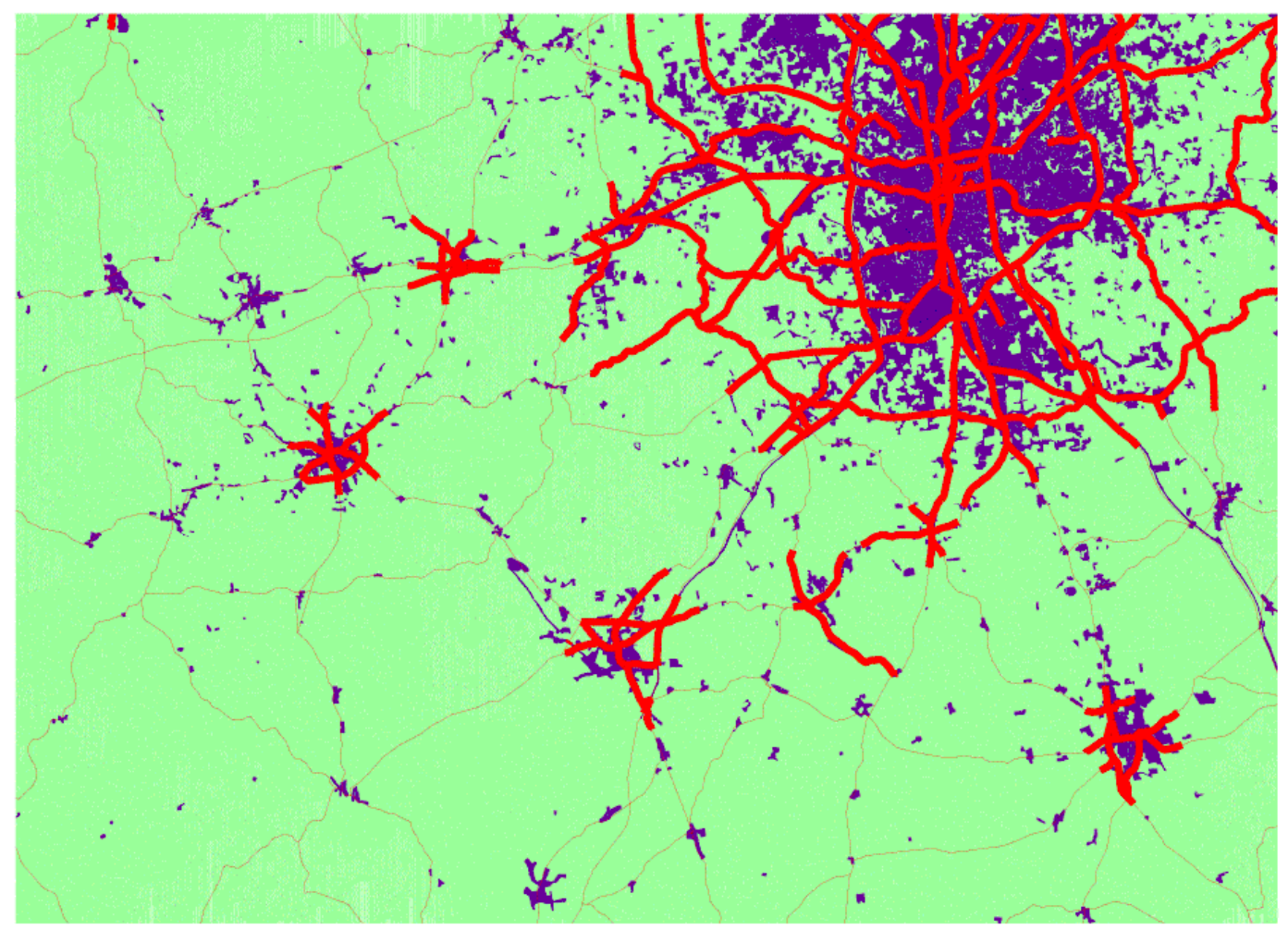

Figure 10. Land Use Change

Without rigorous validation and verification of the input data for this analysis, it is very difficult to determine the quality of the data and their potential usefulness for various purposes. Measuring the uncertainties and errors involved in estimating road widths with respect to pavement, median and right of way, and in deriving mileage of land use types along highways is an important area for future research. Possible methods are suggested below.

To obtain error terms for width estimation, the HPMS samples can be divided into two groups. The first group will be utilized in the process of estimating road widths. After width for each of the road links has been estimated, the second group of the samples will be applied to check errors resulting from width estimation by comparing the estimates for these links to their HPMS values. Bias and error variance could then be directly computed:

$M_{j}=\sum_{i}\left(w_{i j}-w_{i j}^{\prime}\right) / N$ 
and

$V_{j}=\sqrt{\sum_{i}\left[\left(w_{i j}-w_{i j}^{\prime}\right)-M_{j}\right]^{2} /(N-1)}$

where $M_{j}$ represents the mean error for the estimation of the width of type $j$ (pavement, median, right of way), $w_{i j}$ and $w_{i j}$ ' represent the sampled width and the estimated width for sample $i$ and for the width of type $j . N$ is the total number of samples used for error term estimation. $V j$ is the standard deviation of the error for the estimation of the width of type $j$.

Uncertainties related to derived mileage of land use types along highways may occur due to map distortions and attribute errors of both the NHPN and the LULC maps. Attribute errors are largely a problem for the LULC maps and primarily due to their lack of currency. The results of a comparison of land use types identified with land use maps and rural and urban flags that are currently represented in the NHPN can be used as one of the indicators for land use changes. For future research, two approaches can be explored. The first approach is to make use of newly acquired remotely sensed data, which, in general, contain accurate information about current land use patterns. Another approach is to utilize land use modeling tools as those suggested by Berechman and Small (1988), Southworth (1995), and Watterson (1993). These modeling tools will allow a reasonable estimation of land use changes. To obtain estimates of uncertainties related to map distortions, ideally both the dislocations of the NHPN and LULC maps would be measured in the real world, and their effects evaluated. But such a task is too expensive. Instead, we propose a simulation procedure to solve the problem (see Hunter and Goodchild, 1996).

As map scales for both the land use maps and the NHPN are known, their mean errors of map dislocations can be estimated. Assuming that these errors follow recognizable distributions, simulation can be used to generate coordinate shifts to mimic these errors and compute the impacts on classification errors. By combining the above methods, confidence bounds could be derived for the cross-classified land use estimates. With improved land use data it should then be possible to create land use estimates for the national transportation infrastructure for every mode, not just highways. 


\section{REFERENCES}

Anderson, J. R., E. E. Hardy, J. T. Roach, and R. E. Witmer. (1976). A Land Use and Land Cover Classification System for Use with Remote Sensor Data. U.S. Geological Survey Professional Paper 964, U. S. Government Printing Office, Washington, DC.

Berechman, J. and K. A. Small. (1988). "Modeling Land Use and Transportation: An Interpretive View for Growth Areas," Environment and Planning A, 20.10: 12851309.

Hunter, G. J. and M. F. Goodchild. (1996). "A New Model for Handling Vector Data Uncertainty in Geographic Information Systems," Journal of the Urban and Regional Information Systems Association, 8.1.

Maggi, R. (1994). "Environmental Implications of Missing Transport Networks in Europe," Transportation Research, 28A.4: 343-351.

Southworth, F. A. (1995). Technical Review of Urban Land Use-Transportation Models as Tools for Evaluating Vehicle Travel Reduction Strategies, ORNL6881, Oak Ridge National Laboratory, Oak Ridge, Tennessee.

(U.S. DOT/BTS) U.S. Department of Transportation, Bureau of Transportation Statistics. (1996). Transportation Statistics Annul Report, Washington, DC.

(U.S. DOT/BTS) U.S. Department of Transportation, Bureau of Transportation Statistics. (1998). Transportation Statistics Annul Report, Washington, DC.

(U.S. EPA) U.S. Environment Protection Agency. (1999). Indicators of the Environmental Impacts of Transportation, Policy (2126), Washington, DC.

Verhoef, E. (1994). "External Effects and Social Costs of Road Transport," Transportation Research, 28A.4: 273-287.

Watterson, W.T. (1993). "Linked Simulation of Land Use and Transportation Systems: Developments and Experience in the Puget Sound Region," Transportation Research, 27A.3: 193-206. 


\section{APPENDIX A. Land Use Classification}

\begin{tabular}{|c|c|}
\hline Land Use Type & Land Use Code \\
\hline Urban and Built-up Land & 1 \\
\hline Agricultural Land & 2 \\
\hline Rangeland & 3 \\
\hline Forestland & 4 \\
\hline Water & 5 \\
\hline Wetland & 6 \\
\hline Barren Land & 7 \\
\hline Tundra & 8 \\
\hline Perennial Snow or Ice & 9 \\
\hline Unknown & 10 \\
\hline
\end{tabular}




\section{APPENDIX B. Highway Functional Classes}

\begin{tabular}{|c|c|}
\hline Functional Class & Class Code \\
\hline Rural Principal Arterial - Interstate & 1 \\
\hline Rural Principal Arterial - Other & 2 \\
\hline Rural Minor Arterial & 6 \\
\hline Rural Major Collector & 7 \\
\hline Rural Minor Collector & 8 \\
\hline Rural Local & 9 \\
\hline Urban Principal Arterial - Interstate & 11 \\
\hline Urban Principal Arterial - Other Freeways \& Expressways & 12 \\
\hline Urban Principal Arterial - Other & 14 \\
\hline Urban Minor Arterial & 16 \\
\hline Urban Collector & 17 \\
\hline Urban Local & 19 \\
\hline Unknown & 20 \\
\hline
\end{tabular}




\section{APPENDIX C. Miles and Areas by Land Use Types}

$\begin{array}{rrrrr}\text { Landusetype } & \text { miles } & \text { parent(ades) } & \text { nædan(ades) } & \text { rest RaN(ades) } \\ 1 & 105060 & 605241 & 268488 & 1359528 \\ 2 & 173885 & 831911 & 178688 & 1754679 \\ 3 & 52597 & 236247 & 48628 & 708818 \\ 4 & 86987 & 407507 & 87312 & 829869 \\ 5 & 3362 & 16034 & 4218 & 33509 \\ 6 & 5845 & 29721 & 9391 & 61622 \\ 7 & 4298 & 23140 & 9529 & 57042 \\ 8 & 33 & 125 & 16 & 243 \\ 9 & 0 & 2 & 0 & 6 \\ 10 & 4537 & 23119 & 6690 & 43534 \\ \text { Total } & 436610 & 2173052 & 612965 & 4848854\end{array}$




\section{APPENDIX D. Miles and Areas by Functional Classes}

$\begin{array}{rrrrr}\text { Funtional dass } & \text { miles } & \text { pavertit (ades) } & \text { nedan(ades) } & \text { rest RaN(ades) } \\ 1 & 31669 & 296657 & 247502 & 729017 \\ 2 & 98969 & 528724 & 124221 & 1206964 \\ 6 & 132202 & 556162 & 27531 & 1152755 \\ 7 & 36 & 157 & 0 & 318 \\ 8 & 1 & 4 & 0 & 14 \\ 11 & 13258 & 106891 & 61024 & 335030 \\ 12 & 7481 & 51345 & 28286 & 154773 \\ 14 & 52423 & 235136 & 66405 & 461291 \\ 16 & 2451 & 11363 & 2785 & 18609 \\ 17 & 7 & 25 & 0 & 34 \\ 19 & 1 & 3 & 0 & 5 \\ 20 & 98106 & 386578 & 55207 & 790038 \\ \text { Total } & 436610 & 2173052 & 612965 & 4848854\end{array}$




\section{APPENDIX E. Average Widths by Land Use Types}

$\begin{array}{rrrr}\text { Landusetype } & \text { parermt(ft) } & \text { nedan(ft) } & \text { rest RON(ft) } \\ 1 & 47.5 & 21.0 & 106.7 \\ 2 & 39.4 & 8.4 & 83.2 \\ 3 & 37.0 & 7.6 & 111.2 \\ 4 & 38.6 & 8.2 & 78.7 \\ 5 & 39.3 & 10.3 & 82.2 \\ 6 & 41.9 & 13.2 & 86.9 \\ 7 & 44.4 & 18.2 & 109.5 \\ 8 & 30.8 & 4.0 & 59.8 \\ 9 & 31.6 & 0 & 87.2 \\ 10 & 42.0 & 12.1 & 79.1 \\ \text { Overall } & 41.0 & 11.5 & 91.6\end{array}$




\section{APPENDIX F. Average Widths by Functional Classes}

$\begin{array}{rrrr}\text { Funtional dass } & \text { parenet(ft) } & \text { nedan(ft) } & \text { rest RON(ft] } \\ 1 & 77.2 & 64.4 & 189.9 \\ 2 & 44.0 & 10.3 & 100.6 \\ 6 & 34.7 & 1.7 & 71.9 \\ 7 & 35.6 & 0 & 71.8 \\ 8 & 28.0 & 0 & 86.9 \\ 11 & 66.5 & 37.9 & 208.5 \\ 12 & 56.6 & 31.2 & 170.7 \\ 14 & 37.0 & 10.4 & 72.6 \\ 16 & 38.2 & 9.3 & 62.6 \\ 17 & 28.1 & 0.8 & 37.4 \\ 19 & 27.4 & 0 & 48.5 \\ 20 & 32.5 & 4.6 & 66.4 \\ \text { Overall } & 41.0 & 11.5 & 91.6\end{array}$




\section{APPENDIX G. Areas by Highway Type by Land Use Type}

Functiond landuse

Class type

\begin{tabular}{|c|c|c|}
\hline & type & paveret(ares) \\
\hline 1 & 1 & 157711 \\
\hline 1 & 2 & 66533 \\
\hline 1 & 3 & 28443 \\
\hline 1 & 4 & 32619 \\
\hline 1 & 5 & 1207 \\
\hline 1 & 6 & 2968 \\
\hline 1 & 7 & 4234 \\
\hline 4 & 8 & 8 \\
\hline 1 & 9 & 0 \\
\hline 1 & 10 & 2931 \\
\hline . & 1 & 70465 \\
\hline 2 & 2 & 253498 \\
\hline 2 & 3 & 66828 \\
\hline O & 4 & 115602 \\
\hline 0 & 5 & 3083 \\
\hline 2 & 6 & 9617 \\
\hline 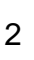 & 7 & 4634 \\
\hline . & 8 & 28 \\
\hline 2 & 9 & 0 \\
\hline 2 & 10 & 4965 \\
\hline 6 & 1 & 53000 \\
\hline 6 & 2 & 286990 \\
\hline 6 & 3 & 65991 \\
\hline 6 & 4 & 130803 \\
\hline 6 & 5 & 2835 \\
\hline
\end{tabular}

\begin{tabular}{|c|c|}
\hline nedan(ades) & rest RON(ares) \\
\hline 129455 & 388245 \\
\hline 53966 & 148043 \\
\hline 26513 & 78598 \\
\hline 27666 & 85340 \\
\hline 816 & 2582 \\
\hline 2893 & 7311 \\
\hline 3643 & 11822 \\
\hline 3 & 48 \\
\hline 0 & 0 \\
\hline 2544 & 7025 \\
\hline 23929 & 134714 \\
\hline 58662 & 564533 \\
\hline 8221 & 217076 \\
\hline 26904 & 246038 \\
\hline 795 & 6476 \\
\hline 3211 & 19668 \\
\hline 1408 & 10917 \\
\hline 11 & 77 \\
\hline 0 & 0 \\
\hline 1074 & 7461 \\
\hline 4059 & 93482 \\
\hline 14653 & 572339 \\
\hline 2224 & 209677 \\
\hline 5572 & 237200 \\
\hline 122 & 5733 \\
\hline
\end{tabular}




\section{Funtiond landuse}

Class type

6

$\begin{array}{ll}6 & 7\end{array}$

68

69

610

$7 \quad 1$

72

73

74

75

76

$\begin{array}{ll}7 & 7\end{array}$

78

79

$7 \quad 10$

81

82

83

84

85

86

$\begin{array}{ll}8 & 7\end{array}$

$8 \quad 8$

89

810

$11 \quad 1$

112

11 paverert(arres)

8410

3826

72

2

4230

18

135

0

4

0

0

0

0

0

0

(

1

3

0

0

0

0

0

0

0

0

76640

12731

2695 nedar(arres)

563

190

0

0

145

0

0

0

0

0

0

0

0

0

0

0

0

0

0

0

0

0

0

0

0

40783

8675

2021 rest RaN(ares)

16891

9283

79

5

8061

38

271

0

8

0

0

0

0

0

0

4

10

0

0

0

0

0

0

0

0

242679

39346

7441 
Funtiond landuse

Class type

115

116

$11 \quad 7$

118

119

$11 \quad 10$

$12 \quad 1$

122

123

124

125

126

127

128

129

$12 \quad 10$

$14 \quad 1$

142

143

144

145

$14 \quad 6$

$14 \quad 7$

148

149

$14 \quad 10$

16 penenert(acres)

9735

939

594

2221

0

0

1332

28548

11101

2393

6658

568

627

1052

0

0

395

148207

43958

6869

24241

2121

1981

3638

0

0

4118

6495 nedan(adres)

6257

482

394

1679

0

0

729

14959

6267

1246

3820

332

472

693

0

0

493

40886

12556

2366

6612

665

921

1273

0

0

1123

1814
restPON(arres)

30669

2698

1959

6419

\section{0}

0

3815

84627

33907

7449

20384

2131

1671

3235

0

0

1365

288064

89786

16561

44848

3982

4085

7627

0

0

6336

10557 
Funtiond landuse

Class type

$\begin{array}{ll}16 & 2 \\ 16 & 3 \\ 16 & \\ 16 & 5 \\ 16 & \\ 16 & \\ 16 & \\ 16 & 9 \\ 16 & 10\end{array}$

$17 \quad 1$

$17 \quad 2$

$17 \quad 3$

$17 \quad 4$

$17 \quad 5$

$17 \quad 6$

$17 \quad 7$

$17 \quad 8$

$17 \quad 9$

$17 \quad 10$

$19 \quad 1$

$19 \quad 2$

$19 \quad 3$

194

$19 \quad 5$

196

197

$19 \quad 8$

19 pavenert(acres)

2032

695

1414

93

105

203

0

0

322

13

10

1

1

0

0

0

0

0

0

0

3

0

0

0

0

0

0

0 nedan(acres)

451

86

298

21

26

51

0

0

34

0

0

0

0

0

0

0

0

0

0

0

0

0

0

0

0

0

0

0 rest RON(adres)

3433

1071

2479

178

199

314

0

0

374

16

15

\section{1}

0

0

0

0

0

0

0

0

5

0

0

0

0

0

0

0 
Functiond landuse Class type

$\begin{array}{lr}19 & 10 \\ 20 & 1 \\ 20 & 2 \\ 20 & 3 \\ 20 & 4 \\ 20 & 5 \\ 20 & 6 \\ 20 & 7 \\ 20 & 8 \\ 20 & 9 \\ 20 & 10\end{array}$

pavenert(acres)

0

64139

154912

62330

86427

5184

5414

3329

15

0

4824 nedan(acres)

0

12600

23456

5947

10179

981

907

590

0

0

544 rest $\mathrm{RON}$ (adres)

0

117099

302985

170940

162897

9726

9834

7422

38

0

9092 


\section{APPENDIX H. State Fips and Name Code}

(Area in this table is the land area for the entire state, not for highway land use)

\begin{tabular}{|c|c|c|}
\hline SIRPS NAME & STATECQE & AREA(SQM) \\
\hline 1 Alabama & $\mathrm{AL}$ & 132948 \\
\hline 2 ALASKA & AK & 1637666 \\
\hline 4 Arizona & $A Z$ & 294201 \\
\hline 6 California & $\mathrm{CA}$ & 405108 \\
\hline 8 Colorado & $\mathrm{CO}$ & 270326 \\
\hline 9 Connecticut & CT & 13011 \\
\hline 10 Delaware & $\mathrm{DE}$ & 5224 \\
\hline 11 District of Columbia & $\mathrm{DC}$ & 172 \\
\hline 12 Florida & $\mathrm{FL}$ & 144887 \\
\hline 13 Georgia & $\mathrm{GA}$ & 152022 \\
\hline 15 HAWAll & $\mathrm{HI}$ & 336 \\
\hline 16 Idaho & ID & 215492 \\
\hline 17 Illinois & $\mathrm{IL}$ & 145802 \\
\hline 18 Indiana & $\mathbb{I N}$ & 93809 \\
\hline 19 lowa & IA & 145176 \\
\hline 20 Kansas & KS & 213044 \\
\hline 21 Kentucky & KT & 105144 \\
\hline 22 Louisiana & LA & 119705 \\
\hline 23 Maine & ME & 83676 \\
\hline 24 Maryland & $\mathrm{MD}$ & 26146 \\
\hline 25 Massachusetts & MA & 20394 \\
\hline 26 Michigan & Ml & 42167 \\
\hline 27 Minnesota & $\mathrm{MN}$ & 218444 \\
\hline 28 Mississippi & MS & 123197 \\
\hline 29 Missouri & MO & 181349 \\
\hline 30 Montana & MT & 380038 \\
\hline
\end{tabular}




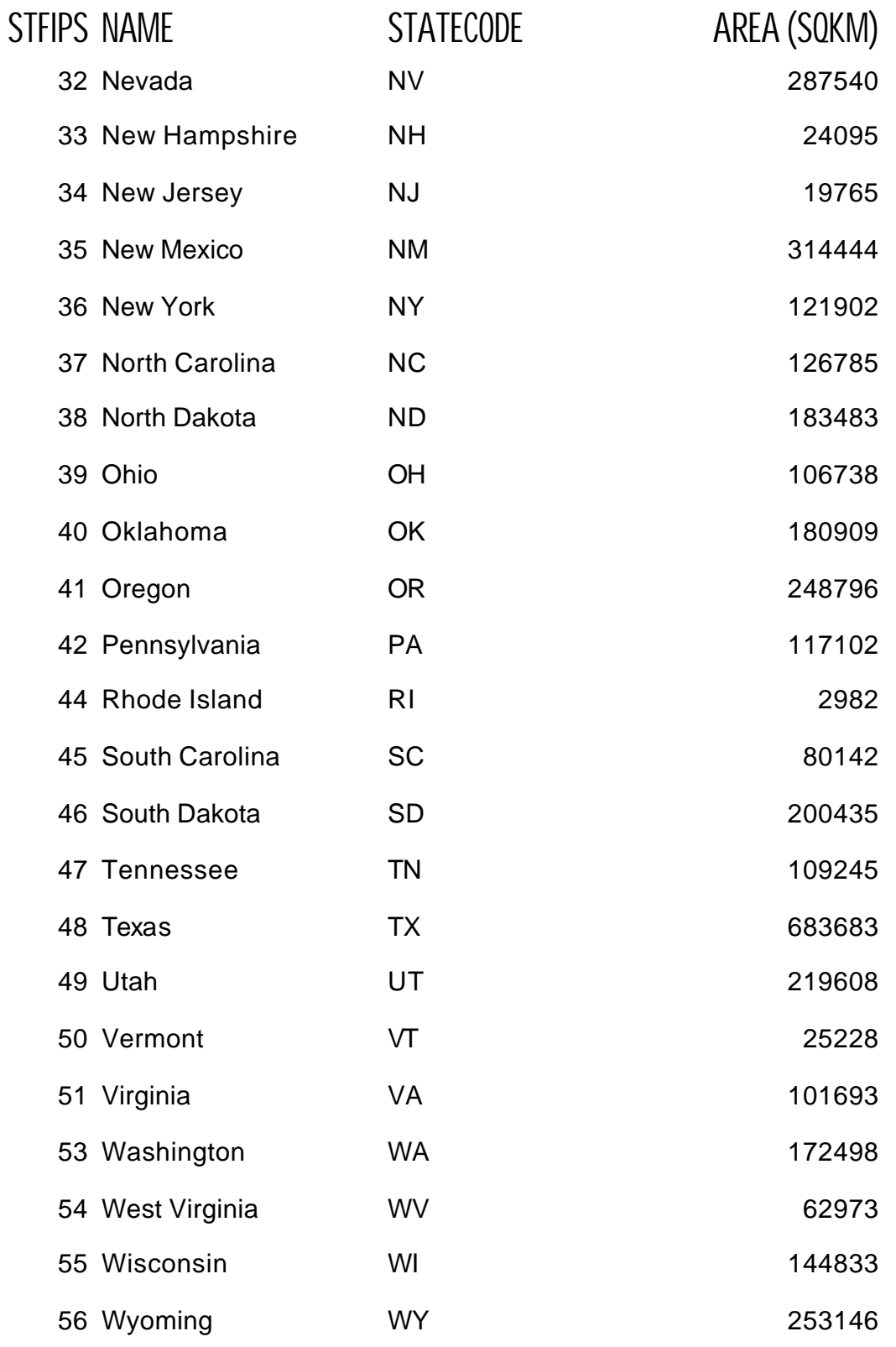




\section{INTERNAL DISTRIBUTION}

1. S.M. Chin

2. G.E. Courville

3. T.R. Curlee

4. J.E. Dobson

5. D.L. Greene

6. P.S. Hu

7. H.L. Hwang

8. R.M. Lee

9. C.I. Moser

\author{
10. B.E. Peterson \\ 11. R.B. Shelton \\ 12. F. Southworth \\ 13. T.J. Wilbanks \\ 14-33. D.Xiong \\ 34. Central Research Library \\ 35. Document Reference Section \\ 36. Laboratory Records \\ 37. Laboratory RecordsCRC
}

\section{EXTERNAL DISTRIBUTION}

38. L.A. Abron, President, PEER Consultants, P.C., 1460 Gulf Blvd., $11^{\text {th }}$ Floor, Clearwater, FL 34630

39. S.L. Cutter, Director, Hazards Research Lab, Department of Geography, University of South Carolina, Columbia, SC 29208

40. S.G. Hildebrand, Director, Environmental Sciences Division, Oak Ridge National Laboratory, Post Office Box 2008, Oak Ridge, TN 37831-6037

41. P.R. Rittelmann, FAIA, Executive Vice President, Burt Hill Kosar Rittelmann Associates, 400 Morgan Center, Butler, PA 16001-5977

42. S.F. Tierney, The Economic Resource Group, Inc., One Mifflin Place, Cambridge, MA 02138

43. C.M. Walton, Ernest H.Cockrell Centennial Chair in Engineering and Chairman, Department of Civil Engineering, University of Texas at Austin, E. Cockrell, Jr. Hall I, Suite 4210, Austin, TX 78712-1075

44-53. OSTI, U.S. Department of Energy, P.O. Box 62, Oak Ridge, TN 37831

54. Carol Brandt, Bureau of Transportation Statistics, U.S. Department of Transportation, 400 Seventh Street, S.W., Room 3430, Washington, DC 20590

55. James Getzewich, Federal Highway Administration, U.S. Department of Transportation, 400 Seventh Street, S.W., Room 3306, Washington, DC 20590

56. Roger Petzold, Federal Highway Administration, U.S. Department of Transportation, 400 Seventh Street, S.W., Room 3301, Washington, DC 20590

57. Rolf Schmitt, Bureau of Transportation Statistics, U.S. Department of Transportation, 400 Seventh Street, S.W., Room 3430, Washington, DC 20590

58. Ashish Sen, Bureau of Transportation Statistics, U.S. Department of Transportation, 400 Seventh Street, S.W., Room 3430, Washington, DC 20590 
59. Bruce Spear, Bureau of Transportation Statistics, U.S. Department of Transportation, 400 Seventh Street, S.W., Room 3430, Washington, DC 20590 